\title{
Pesquisa social ou pesquisa qualitativa? Uma dis(des)cu(constru)ss(ç)ão em pauta na saúde coletiva
}

\author{
Social research or qualitative research? A dis(de)cuss(construct)ion \\ on the agenda in collective health
}

Leonardo Carnut ${ }^{1}$

DOI: 10.1590/0103-1104201912013

RESUMO O objetivo deste texto é analisar, inicialmente, por uma vertente crítica, a produção da pesquisa social em saúde coletiva tendo como eixo norteador o 'elo perdido' entre teoria-e-método. Para tanto, optou-se pela modalidade textual de ensaio crítico, inspirada em Adorno e Meneghetti, que a defendem como forma de ultrapassar o pensamento para além das fronteiras do método. Toma-se como ponto de partida a frequente confusão entre 'pesquisa social' e 'pesquisa qualitativa' no campo da saúde coletiva como questão disparadora da reflexão. Ao longo do texto, a reflexão reaviva conceitos, teorias e as técnicas utilizadas na subárea das 'Ciências Sociais e Humanas em Saúde' como forma de discorrer sobre essa (des)conexão. Por fim, são apresentados limites e possibilidades da pesquisa social na saúde coletiva e o papel das Ciências Sociais e Humanas em Saúde na problematização do debate.

PALAVRAS-CHAVE Pesquisa qualitativa. Ciências sociais. Saúde pública. Sociologia. Conhecimento.

ABSTRACT The aim of this text is to analyze, initially, in a critical way, the production of social research in collective health having as its guiding axis the 'missing link' between theory and method. For this purpose, the textual modality of critical essay was chosen, inspired by Adorno and Meneghetti, who defend this modality as a way of overcoming the thought beyond the boundaries of the method. The starting point is the frequent confusion between 'social research' and 'qualitative research' in the field of collective health as a triggering issue for reflection. Throughout the text, the reflection revives concepts, theories and techniques used in the subarea of 'social and human sciences in health' as a way of discussing the (dis)connection. Finally, the limits and possibilities of social research in collective health and the role of social and human sciences in health are presented in problematizing the debate.

KEYWORDS Qualitative research. Social sciences. Public health. Sociology. Knowledge.

1 Universidade Federal de São Paulo (Unifesp) - São Paulo (SP), Brasil.

leonardo.carnut@gmail.com 


\section{Introdução}

Pesquisar é uma forma de compreender o mundo em sua multidimensionalidade. A saúde coletiva, como campo/núcleo de saberes e práticas que advoga para si a chancela da interdisciplinaridade, apresenta na pesquisa social um desafio maior: dialogar entre os diferentes. Tarefa que até hoje os antropólogos penam em realizar.

Assim, sem querer tecer uma visão 'ingênua' sobre o assunto, mas conduzir a batuta para orquestrar um pensamento harmônico e respeitoso sobre a área, é que, 'pensamos' (forma de escrita em 'primeira pessoa do plural' tradicional nas ciências sociais) que seja producente na elaboração de um fio condutor na descrição desse tema. Afinal, como acentua Geertz', entre a profusão de análises, é necessário fazer escolhas. Portanto, uma dessas escolhas será a guia deste estudo.

À guisa de introdução, este texto tem como objetivo analisar, por uma vertente crítica (ainda que inicial), a produção da pesquisa social em saúde, discorrendo sobre tópicos que têm como eixo norteador o 'elo perdido' entre teoria-e-método, o qual é hoje o principal problema da pesquisa social em saúde coletiva.

Para tanto, optou-se pela modalidade textual de ensaio crítico, pela possibilidade de a orientação ser dada não pela busca de respostas ou afirmações verdadeiras, mas pelas perguntas que possam orientar os sujeitos a reflexões mais profundas ${ }^{2}$. Assim, o objetivo deste ensaio é articular ideias, e, nesse sentido, o rigor metodológico não parece ser a forma mais producente de se ensaiar o pensamento. Portanto, inspirou-se em Adorno ${ }^{3}$, quando defende que o ensaio é um momento de escrita que favorece a ultrapassagem de fronteiras culturalmente demarcadas.

Assim, este ensaio está dividido em dez seções que, longe de esgotarem o tema, assinalam caminhos que podem ser trilhados em busca de uma discussão mais profícua quanto à produção do conhecimento sobre o social e à responsabilidade da saúde coletiva (em especial, da subárea das Ciências Sociais e Humanas em Saúde - CSHS) nesse empreendimento.

\section{Pesquisa 'social' ou 'qualitativa'?}

Um tema que habita o imaginário social do grupo científico ${ }^{4}$ que se dedica à produção do conhecimento na área das ciências sociais e humanas é a compreensão (particularmente, não unívoca) do que vem a ser 'pesquisa social'. O debate se acalenta quando se inserem outros sujeitos produtores de ciência, filiados a outra ordem de discursar5, como no caso dos profissionais de saúde. Doutos em suas matrizes analíticas (de base newtoniano-cartesiana, vitalista-monista, hipotético-dedutiva) ${ }^{6-8}$, tendem a importar a lógica de produção de conhecimento de suas áreas para a compreensão do social, o que, tradicionalmente, vem acarretando tensões entre pesquisadores da saúde coletiva, em especial, aqueles que se localizam nas CSHS.

Em que pese a interdisciplinaridade constituinte do 'fazer saúde coletiva', a prática de pesquisa necessita de cuidados teórico-epistemológicos importantes caso não se queira incorrer no ecletismo autofrustrado'. Uma assertiva clássica é considerar todas e quaisquer formas de realizar 'pesquisa qualitativa' (em sua máxima expressão) como 'pesquisa social'. Essa 'cantilena' tem invadido o cenário de pesquisa, e muitos se consideram, inclusive, pertencentes às 'ciências sociais ou humanas' apenas por abordarem seus objetos de pesquisa com o uso da metodologia qualitativa.

Nesses momentos, os clássicos nos ajudam, como diria Alexander ${ }^{9}$. Recorrendo a Minayo ${ }^{10}$, pesquisadora brasileira reconhecida por problematizar a construção do conhecimento nas CSHS, a 'pesquisa social' é dotada de consciência histórica, enquanto a 'pesquisa qualitativa' pode restringir-se apenas à captura da(s) subjetividade(s) do fenômeno em tela. Parsons ${ }^{11}$ já nos esclarecia que a pesquisa social 
pode ser tanto quantitativa como qualitativa. Não há problemas quanto ao método per se, o que interessava para este autor é a forma de aproximar-se dos fenômenos mais coerentemente com a maneira pela qual o processo explicativo será edificado para responder à pergunta encetada.

Por isso, pensar nas características da pesquisa social, assim como de quaisquer outras áreas de pesquisa, é (re)pensar nos referenciais ontoepistemológicos que sustentam suas teses fundamentais e derivar, dessas premissas, as teorias, os conceitos e, por conseguinte, os métodos a serem aplicados. Por mais que Minayo ${ }^{10}$ contundentemente venha reforçando a tese de que o 'objeto' das ciências sociais é eminentemente 'qualitativo', nada impede que o possa ser feito por uma abordagem quantitativa, desde que se mostre necessária e coerente. Mas, para isso, é essencial aprofundarmos um pouco mais sobre as características do conhecimento científico que subjazem essa discussão ${ }^{12-15}$.

\section{Breves aspectos sobre o conhecimento científico}

Lança-se a tese de que é possível compreender a equivalência 'pesquisa social igual à pesquisa qualitativa' através de algumas questões fundamentais sobre a produção do conhecimento científico. A tradução da constituição da ciência moderna se baseia nos cânones do pensamento racionalista (de origem greco-romana, ainda estrito à filosofia e 'reinaugurado' no iluminismo, especialmente com o advento do método). O desenvolvimento dessa forma de pensar o mundo (e, portanto, a ciência como discurso hegemônico) considera o método como 'fetiche', assim como todos seus preceitos fundamentais, a saber: a) a valorização da experiência sensível como forma de apreensão do fenômeno (ver para descrever); b) a relação de separação e independência entre sujeito-objeto; c) a neutralidade na constituição do saber científico; e d) a busca de leis gerais e imutáveis que regem a natureza e os homens nas suas formas de viver.
O pensamento dos pesquisadores na área da saúde coletiva, por mais que se tenha avançado nesse aspecto, ainda se encontra colonizado por essa construção do saber herdada das ciências naturais e que, insistentemente, reifica o social. O fetiche do método, na saúde coletiva (e suas sobrevivências nas CSHS), reitera o lugar da necessidade de 'aplicar' o método em detrimento da 'compreensão da teoria'. Não afortunadamente, as 'análises' (e, apenas nessa 'operação' metodológica, caberiam exaustivas observações, que não seriam oportunas neste momento) realizadas pelos que iniciam as CSHS apelam para o 'método' (fechado, bem delineado, protocolar) como forma de instituir-se como membro desse grupo científico. No pleito desse estatuto, vale a pecha de considerar (ou, diga-se, 'equivaler') a 'pesquisa qualitativa' como se fosse 'pesquisa social'.

Como já descrito por autores mais experientes ${ }^{12-17}$ e que transitam melhor nessa área fronteiriça, fazer pesquisa social é considerar, também, que outros pressupostos de construção do conhecimento científico devam ser levados em consideração. Então, não se trata de 'um' ou 'outro', e, sim, 'um' e 'outro'. Por isso, ter em mente que os cânones acima descritos devem obrigatoriamente dialogar com: a) a valorização da expressão subjetiva e sócio-histórica do fenômeno (ouvir para compreender); b) assumir a intrínseca relação de interdependência entre sujeito e objeto; c) compreender a ausência de neutralidade axiológica na construção do conhecimento científico; e d) buscar a particularidade das expressões fenomênicas e sua capacidade de dotar sentidos e significados à vida do homem e sua relação com o mundo.

\section{O arcabouço teórico e a estruturação do trabalho (e do trabalhador) científico}

Quando se trata de pesquisa científica, é inevitável não pensar nos seus procedimentos 
mais 'operacionais'. É lugar comum na saúde coletiva importar suas formas de produzir os materiais, relatórios de pesquisa, teses e dissertações à luz do que é realizado no âmbito das ciências naturais. Contudo, quando se trata desse lugar híbrido que são as CSHS, é fundamental ter em mente que não é desejável desconsiderar como se pensa a abordagem dos fenômenos sob o rótulo das ciências sociais.

Alguns autores nos esclarecem essa questão ${ }^{\mathbf{1 8}-20}$. Nas ciências sociais e humanas, a noção de totalidade social e seus meandros na experiência individual impõem a difícil tarefa de separação do 'senso comum' do 'conhecimento cientificamente válido'. Dotada de uma 'intimidade' com os sujeitos viventes, as categorias sociais aparecem como parte do nosso cotidiano sem que se reflita muito sobre elas. Abstrair a realidade concreta da experiência social de um indivíduo, a ponto do exercício da autorreflexão e consideração das diversas possibilidades de expressão da vida social, é um esforço que Castro ${ }^{18}$ batiza como uma 'aventura'.

Para Mills ${ }^{19}$, o processo de abstração do 'social' requer mais que uma reflexão autodirigida, mas, sim, um processo de construção de um imaginário. Para o autor, o verdadeiro cientista social é aquele que se debruça na construção de uma 'imaginação sociológica' capaz de compreender o social desde sua totalidade até os eventos mais microssociais. Nesse sentido, para além da autorreflexão, é necessário um constante artesanato intelectual.

Todas essas questões são importantes, pois o 'pensar socialmente' implica diretamente o método e suas variantes operacionais. Afinal, é de se esperar que o pensamento conforme o trabalho científico. Por outro lado, o trabalho científico, repetitivo, cumulativo e aperfeiçoado, de forma mais intensa, conforma o trabalhador da ciência e seu pensamento. Nesse ponto, deve-se atentar para a sedução do método. Com o trabalho científico cada vez mais extenuante, acelerado e, nesse sentido, irrefletido, cair na instrumentalidade do método é uma tendência. Isso é algo que assola particularmente a produção científica em CSHS. Com repertório teórico e modos de produção de conhecimento, em tese, filiados às ciências sociais e humanas, mas com exigência de publicações características da saúde, a instrumentalização metodológica reforça a insistente tese deste artigo. Assim, a separação teoria-método nas CSHS se conforma e torna-se o problema, e, por mais ululante que possa parecer a afirmação que se escuta nas conversas informais de que não é possível separar teoria e método, assistimos ao seu divórcio cotidianamente.

Pensar na produção do conhecimento científico nas CSHS para além desse elo fundamental requer uma estética (em termos de 'criatividade' metodológica) razoável. Não obstante, digressões sobre o método na pesquisa social devem ser sempre pauta de dis(des) cu(constru)ss(ç)ão. Nesse sentido, Feyerband ${ }^{\mathbf{2 1}}$ nos ajuda a compreender como as amarras do método engessam o avanço do conhecimento e descreve quantas 'descobertas' científicas foram feitas quando os seus pesquisadores ultrapassaram as fronteiras endurecidas do rigor metodológico.

\section{As duas vertentes: qualificação e quantificação}

O que está em jogo na discussão da produção do conhecimento científico sobre o social são os interesses que estão escamoteados na compreensão dos fenômenos. Por mais não aparente que isso possa ser no âmbito da quantificação, a questão que subjaz entre as duas é a mesma.

A famosa metáfora da 'falta regulamentar em um jogo de futebol', descrita por Bauer ${ }^{22}$, ilustra bem a questão. Quando se faz a 'falta' em um jogo de futebol, duas torcidas rivais vão interpretar o mesmo fenômeno segundo seus interesses. A torcida de um lado defenderá que a falta foi válida. A do outro, que ela foi simulada. Então, sob o mesmo fenômeno social, é possível uma escala infindável de interpretações, e esse caso demonstra como cada 
uma delas é referente a um interesse específico na construção do conhecimento.

Contudo, o método em si tem uma contribuição sui generis para agravar essa condição. Enquanto os métodos qualitativos se preocupam em como 'qualificar' e 'compreender' os fenômenos em sua existência sócio-historicamente situada, o 'quantitativo' contabiliza e orienta seu olhar aos 'padrões de repetição', a fim de identificar as causas específicas destes. Nessa última tentativa, o 'quantitativo' esconde suas 'opções' nas formas de operacionalizar as variáveis e de interpretar os números em suas tendências centrais e dispersões. A pesquisa qualitativa, no entanto, assume seus valores e os incorpora na análise.

Essas questões têm rebatimentos evidentes na pesquisa na área da saúde coletiva, desde as interpretações dos modelos matemáticos, testes estatísticos usados na epidemiologia até suas formas de apresentação, que permeiam o ideário da área com a insígnia da 'pesquisa desprovida de juízo de valor'. O problema tem residido na determinação do quanto a pesquisa qualitativa vem assumindo esses mesmos parâmetros, mimetizando as formas de produzir ciência da pesquisa quantitativa.

\section{Ética na pesquisa social}

A ética na pesquisa social também apresenta muitas controvérsias. Muito comumente, durante vários anos, a pesquisa na área das ciências sociais e humanas não 'padecia' das análises dos comitês de ética em pesquisa. Contudo, com a Resolução $n^{0} 510 / 2016$, a apreciação pelo Comitê Nacional de Ética em Pesquisa (Conep) das pesquisas sociais com seres humanos passa a ser obrigatória ${ }^{23}$.

Em que se considere esse feito como um avanço, é fundamental problematizá-lo. Flick ${ }^{24}$ catalogou diversos casos de problemas éticos no trabalho com o uso de metodologias qualitativas. O caso mais conhecido tratou de uma pesquisa nos Estados Unidos, que, em pesquisas sobre práticas de encontro entre homossexuais em lugares públicos (costumeiramente chamados de 'banheirão') com fins sexuais, o pesquisador se disfarçava de faxineiro e seguia os homens que entravam no banheiro, para observar suas práticas. Não satisfeito com essa 'invasão', o pesquisador seguia os usuários até seus veículos e, de posse do número da placa do carro, tinha acesso a todos os dados pessoais, o que lhe permitiu enviar-lhes e-mails com questionários para avaliação.

Depois desse cenário de pesquisa estarrecedor, a discussão não passa incólume, e faz-se necessário compreender até que ponto as interações, as relações, em suma, 'o social' é passível de controle ético. Só é possível pensar na flexibilização do controle ético, pois, enquanto prática de pesquisa, a busca de informações, a aplicação de questionários e as entrevistas se assemelham em demasia às interações do cotidiano. Assim, pensar no controle ético sobre 'o social' representa implicações importantes para métodos tradicionalmente cunhados nas ciências sociais e humanas, tais como observação participante, etnografias, tornando bastante questionáveis as medidas de controle, por poderem restringir a sociabilidade em sua forma anfêmera.

'Técnicas de coleta' ou 'Produções intersubjetivas da realidade'? 'Técnicas de análise de dados' ou 'Produções de interpretações paradigmaticamente filiadas'?

Um efeito abusivo da colonização do modo de ser/pensar das ciências naturais na produção qualitativa da saúde tem sido a tecnificação do ato de pesquisa. Considerando-se que as formas de produção de pesquisa social quantitativa possam (e até devem) seguir esse rumo, as formas de produzir pesquisa social qualitativa sofrem solipsismos léxico-semânticos canhestros de toda ordem. Sob os auspícios da técnica, há uma tendência em considerar 'o social' como um 'dado', pronto para ser 'descoberto' (racionalidade da descoberta), o que denota a ideia cartesiana de que o universo é imutável e sua natureza é a estabilidade 22,25. 
O mesmo acontece, infelizmente, com muita frequência, com a forma de analisar o fenômeno. Em que pese a importância da análise (em sentido lógico aristotélico, cartesiano de pensar a 'análise' como forma de 'decomposição das partes'), na pesquisa social qualitativa, o que guia é a '(des-re)construção social do fenômeno na realidade', especialmente por considerar que o ato de se fazer ciência já é, em si mesmo, a construção de um mundo com léxico e discurso próprios ${ }^{5}$. Considerase, então, que o pesquisador social qualitativo deva pensar o social como um 'regime de processos', dinâmicas e contingências que se concretizam num momento e porventura nunca mais se manifestam na mesma forma e conteúdo $22,26,27$.

\section{Principais teorias sociais e suas con- tribuições para ler 'o social' e suas principais formas de construção da pesquisa social}

É conspícuo que pensar a pesquisa social no âmbito da saúde coletiva é um desafio não apenas nas suas divergências ontológicas e paradigmáticas, mas, também, no uso das teorias e das ‘técnicas' e dos 'métodos'. Nesse sentido, assim, em uma brevíssima viagem nas teorias sociais que mais são utilizadas nessa área, pode-se dizer que há um trânsito desde as abordagens clássicas, com Marx e Engels e a sociologia marxista, inspiradora do campo da saúde coletiva em seus primeiros momentos de definição sobre a 'determinação social do processo saúde-doença' ${ }^{\text {'28 }}$. O funcionalismo durkheimiano ${ }^{29}$ pode ser verificado nas análises mais orientadas à matematização, oriundas da epidemiologia convencional ou que com ela dialogam ${ }^{30}$. As abordagens pela teoria weberiana (método Verstehen) são mais utilizadas no âmbito das CSHS, em especial, nos estudos relativos à integralidade ${ }^{31}$.

Há uma forte tendência ao uso das teorias sociais contemporâneas nos últimos anos. A teoria da estruturação, de Giddens ${ }^{32}$, e as análises das instituições sociais (especialmente, a médica) realizadas por Parsons ${ }^{11}$ inspiram as análises na saúde coletiva. Goffman ${ }^{33}$ e os seus célebres trabalhos à luz do interacionismo simbólico também são vistos com bastante simpatia pelos pesquisadores, especialmente entre aqueles mais focados na inter-relação do que os que se preocupam com a distribuição do poder (que se deslocam mais à linha francesa, cujos principais representantes são Foucault e Bourdieu). A fenomenologia de Schütz ${ }^{34}$ e a Grounded Theory de Glasser e Strauss ${ }^{35}$ gozam de alguns simpatizantes.

Reduzindo a discussão apenas à sociologia, há uma tendência de dois polos: um mais moderno, de apelo ao individualismo metodológico, originário em Von $\mathrm{Mises}^{36}$, cuja perspectiva vem penetrando sistematicamente as CSHS via subárea de 'política, planejamento e gestão em saúde'. E outro polo, de tendência a uma sociologia mais pós-moderna, que aposta em autores como Han ${ }^{37}$, Dubet ${ }^{38}$, Touraine ${ }^{39} \mathrm{e}$ Beck $^{\mathbf{4 0}}$. Na tradição marxista, isso fica a cargo dos neomarxistas Žižek ${ }^{\mathbf{4 1}}$ e Mészáros ${ }^{\mathbf{4 2}}$. Em análises mais socioantropológicas, há uma tendência que vem sendo o aporte da antropologia social e cultural, cujos principais autores residem no pensamento interpretativista e/ou hermenêutico, daí emergindo nomes como Geertz $^{\mathbf{1}}$, Sahlins ${ }^{\mathbf{4 3}}$, Wacquant ${ }^{\mathbf{4 4}}$, Hannerz ${ }^{\mathbf{4 5}}$ e Augé46. Contudo, não se desconsideram as forças que os clássicos Lévi-Strauss ${ }^{\mathbf{4 7}}$ e Marcel Mauss ${ }^{\mathbf{4 8}}$ detêm no campo.

Frente a uma diversidade teórica tão extensa, há múltiplas combinações de técnicas que beiram ao infinito. Entre o que se considera como 'forma de produção intersubjetiva da realidade', ou seja, as 'técnicas', a saúde coletiva tem optado por entrevistas qualitativas, grupos focais, observação participante e etnografias. Quanto ao que se considera como 'narrativas sobre o objeto' (ou seja, as 'análises'), as mais utilizadas são as análises de conteúdo (filiadas às diversas escolas), análise de discurso, análises documentais e análises argumentativas. Em que pese a necessidade de tantos outros métodos em um campo interdisciplinar, tal qual se denomina a saúde coletiva, 
há um predomínio do uso dessas 'ferramentas' citadas quando se trata da investigação dos seus métodos de produção do saber.

\section{Outros métodos: os métodos híbri- dos? Onde classificá-los? 0 registro do 'social' pelo som, pela imagem e pelo virtual}

Um avanço significativo tem sido o uso de outros métodos que iniciam sua chegada no âmbito da saúde coletiva. Alguns, já com mais tempo, são os chamados métodos 'híbridos'.

Por serem considerados métodos que combinam análises quantitativas com qualitativas, esses métodos se preocupam com outra forma de produzir conhecimento que tenta integrar (ou triangular) ${ }^{10}$ visões de diversas formas de apreensão. Entre eles, a pesquisa-ação ${ }^{49}$ e os estudos de caso ${ }^{50,51}$ são os mais frequentes. Na última década, a proposição do discurso do sujeito coletivo (que se ancora na teoria das representações sociais de Serge Moscovici), elaborada por Lefèvre ${ }^{52}$, ganhou vários adeptos.

Não há (ainda) na saúde coletiva a tradição do uso de métodos que trabalhem com som ou imagens de forma cotidiana, estando tais métodos ainda restritos ao uso das ciências sociais e humanas em geral. Contudo, o uso das chamadas 'netnografias' ou etnografias virtuais vem adentrando o cenário da saúde coletiva com alguma expressão. Na tentativa de considerar o 'ambiente virtual' como 'campo de interação social', esse método aparenta ser uma aposta importante, especialmente para aqueles que desejam avançar na investigação sobre as 'novas formas de sociabilidade'53.

\section{A qualidade da pesquisa social qualitativa}

Diante de todo esse repertório, é comum a pergunta: mas qual investigação me traz dados mais fecundos? A partir desse questionamento, vem-se discutindo cada vez mais na área a importância da qualidade da pesquisa social qualitativa, principalmente no que tange ao ‘elo perdido' entre método e teoria.

O interesse dos pesquisadores em saúde sobre o fato de sua pesquisa ser boa ou suficiente, das instituições financeiras em saber o que financiar ou não, a decisão dos editores em saber o que se deve publicar ou não e a decisão dos leitores em ter confiança nos trabalhos produzidos trouxeram ao proscênio a questão da qualidade de forma feroz.

Os estudos mais avançados nessa área vêm produzindo esforços ao considerar o processo de controle de qualidade das análises ${ }^{22}$ e os processos de validação qualitativa ${ }^{54}$, como no caso do Casp (Critical Apprasial Skills Programme), e buscam orientar a leitura de artigos qualitativos e outros métodos que tentam minimizar as falácias de interpretação de dados históricos e sociais ${ }^{54}$. No entanto, há diversas controvérsias sobre a possibilidade de considerar 'procedimentos metodológicos' de verificação de qualidade justamente pelos seus padrões estandardizados e que raramente poderiam ser 'adequados' a 'percursos metodológicos' tão diversos.

Diante desse imbróglio, as saídas têm sido o uso das metassínteses qualitativas como forma de revisar o conhecimento sobre um tema e/ou seus processos metodológicos, deixando a cargo dos leitores a arbitragem sobre a relevância ou não dos resultados sumarizados ou do método revisado como forma de garantir a isenção de 'encapsulamento pelo procedimento'24,54.

\section{Pesquisa social em saúde coletiva: seus limites e possibilidades}

Nessa seara da pesquisa social (com foco, aqui, na pesquisa qualitativa), há diversos limites e possibilidades que a saúde coletiva deve observar/ reconhecer caso queira avançar nessa discussão. Entre os limites, tem-se: a hegemonia dos critérios oriundos da epidemiologia nos comitês editoriais dos periódicos científicos em saúde 
coletiva; o formato tradicional de apresentação de artigos (introdução, método, resultados, discussão e conclusão); a discussão do uso das bases teóricas e suas articulações como momento da análise (dado seu costumeiro distanciamento); a equalização dos Qualis das revistas, evitando discrepâncias de qualificação 'A' nas ciências sociais e humanas quando o mesmo periódico é classificado como 'B e C' na saúde coletiva; o debate acerca do produtivismo no campo da saúde coletiva; a instituição do regime classificatório da ciência política; e a necessidade de articulação com o Fórum Permanente de Pós-graduação em Saúde Coletiva, Editores de Revistas em Saúde Coletiva e o Conep, como maneira de difundir o conhecimento.

Um grande limite considerado como um desafio dos próximos anos, ainda que não esteja em pauta devido a todos os anteriormente relatados, refere-se à 'conexão interparadigmática’ na compreensão da saúde como objeto interdisciplinar. Mesmo considerando análises sobre a saúde por diversos paradigmas distintos, a verdadeira construção do conhecimento interdisciplinar se assenta na conexão interpretativa entre os paradigmas sobre o mesmo fenômeno. Quando a saúde coletiva puder alcançar esse estágio de compreensão da saúde, ficará mais evidente o quanto o caráter político das diferentes interpretações expõe a saúde como campo de intensa disputa e possibilita interpenetrar paradigmas de forma 'aceitável', sem ecletismos nem bricolagens, mas, sim, aceitando a interdisciplinarização de forma absoluta.

Entre as possibilidades, é fundamental ter em mente que o aumento do grau de institucionalização do Qualis livros, as pressões sobre as instâncias decisórias (Conselho Nacional de Desenvolvimento Científico e Tecnológico CNPq) a garantir maior equidade, no sentido de valorizar as revistas em saúde coletiva nacionais e latino-americanas, as demandas junto aos periódicos de saúde coletiva, o aumento do número de revisores nacionais e latino-americanos com enfoque das CSHS, o apoio à expansão das linhas de pesquisa em
CSHS na graduação e na pós-graduação e as práticas de produção do conhecimento de forma democrática e coletiva - levando-se em consideração que as pesquisas devem ser 'com' os seres humanos, e não 'em' seres humanos - são elementos importantes na construção do caminho que está por vir55.

\section{Considerações finais}

Em face de todos os elementos aqui trazidos, é importante admitir que a saúde coletiva tem se esforçado sobremaneira para conseguir produzir um verdadeiro diálogo interdisciplinar que favoreça a apreensão do fenômeno saúde de forma múltipla, plural e democrática.

Considera-se que esse exercício reflexivo tenha conduzido a analisar melhor a produção da pesquisa social em saúde, criticando suas estagnações e apontando seus avanços, por vezes, conduzindo um 'reatar' necessário, um encontro do 'elo perdido', que, sem dúvida, hoje, é o problema mais evidente da pesquisa social no âmbito da saúde coletiva.

Contudo, há de se entender que o desafio posto é maior. É fazer com que as CSHS sejam visibilizadas como produtoras de conhecimento inconteste, já que a força da saúde coletiva advém da singularidade desse olhar que compõe a especificidade da saúde pelos olhos do coletivo.

Assim sendo, em tempos austeros, de derrocada democrática e retrocessos sociais, o papel político da pesquisa social está mais em pauta do que nunca. É somente através da problematização, do refinamento e da busca incessante de abarcar a totalidade do social que a pesquisa social em saúde coletiva garantirá seu reconhecimento e sua relevância na academia e na vida.

\section{Colaboradores}

Carnut L (0000-0001-6415-6977)* é responsável pela elaboração do manuscrito.
*Orcid (Open Researcher and Contributor ID). 


\section{Referências}

1. Geertz C. A interpretação das culturas. São Paulo: LTC; 1989.

2. Meneghetti FK. O que é um ensaio teórico? Rev. Adm. Contemp. 2011; 15(2):320-322.

3. Adorno TW. Notas de literatura. Rio de Janeiro: Editora $34 ; 2003$

4. Bourdieu P. Razões Práticas: sobre a teoria da ação. Campinas: Papirus; 1996.

5. Foucault M. A ordem do discurso. 3. ed. São Paulo: Loyola; 1996.

6. Tavares C. A matriz invisível da saúde. In: Tavares C. Iniciação à visão holística. 3. ed. Rio de Janeiro: Record; 1997. p. 76-92.

7. Portocarrero V. As Ciências da Vida: de Canguilhem a Foucault. Rio de Janeiro: Fiocruz; 2009.

8. Duarte LFD. A propósito da novidade dos objetos e realidades nas ciências sociais contemporâneas. In: Canesqui AM. Dilemas e desafios das ciências sociais na Saúde Coletiva. São Paulo: Hucitec/Rio de Janeiro: Abrasco; 1995. p. 69-77.

9. Alexander JC. A importância dos clássicos. In: Giddens A, Turner J, organizadores. Teoria Social Hoje. São Paulo: UNESP; 1999. p. 23-89.

10. Minayo MCS. Pesquisa social: teoria, método e criatividade. 13. ed. Petrópolis: Vozes; 1999.

11. Parsons T. Social structure and personality. Glencoe: Free Press; 1970.

12. Mondin B. O problema gnosiológico. In: Mondin B. Introdução à filosofia: problemas, sistemas, obras, autores. São Paulo: Paulus; 1980. p. 21-38.

13. Carvalho MAR. Institucionalização das ciências sociais brasileiras e o campo da saúde. In: Canesqui AM. Dilemas e desafios das ciências sociais na Saúde Co- letiva. São Paulo: Hucitec/ Rio de Janeiro: Abrasco; 1995. p. 49-67.

14. Luz MT. Novas realidades em saúde, novos objetos em ciências sociais. In: Canesqui AM. Dilemas e desafios das ciências sociais na Saúde Coletiva. São Paulo: Hucitec/ Rio de Janeiro: Abrasco. 1995, p. 79-85.

15. Cotrim G. Teoria do Conhecimento. In: Cotrim G. Fundamentos de Filosofia: história e grandes temas. 16. ed. São Paulo: Saraiva; 2006. p. 54-61.

16. Oliva A. Teoria do conhecimento. Rio de Janeiro: Zahar; 2011.

17. Durozoi G, Roussel A. Dicionário de filosofia. 5. ed. Campinas: Papirus; 1993.

18. Castro CM. Memórias de um orientador de tese. In: Nunes EO. A aventura sociológica. Rio de Janeiro: Zahar; 1978. p. 307-326.

19. Mills W. A imaginação sociológica - do artesanato intelectual. 6. ed. Rio de Janeiro: Zahar; 1982.

20. Oliveira PS. Caminhos de construção da pesquisa em Ciências Humanas. In: Oliveira PS. Metodologia das ciências humanas. São Paulo: UNESP/Hucitec, 1998. p. 17-26.

21. Feyerband P. Contra o método - esboço de uma teoria anárquica da teoria do conhecimento. Rio de Janeiro: Francisco Alves; 1977.

22. Bauer MW. Pesquisa qualitativa com texto, imagem e som - um manual prático. 8. ed. Petrópolis: Vozes; 2010.

23. Brasil. Resolução $n^{0} 510$, de 7 de abril de 2016. Dispõe sobre as normas aplicáveis a pesquisas em Ciências Humanas e Sociais [internet]. Diário Oficial da União 24 Maio 1991. [acesso em 2018 jul 11]. Disponível em: http://conselho.saude.gov.br/resolucoes/2016/reso510.pdf. 
24. Flick U. Ética na pesquisa qualitativa. In: Flick U. Introdução à pesquisa qualitativa. 3. ed. Porto Alegre: Artmed; 2009, p. 50-58.

25. Bel J. Projeto de pesquisa: guia para pesquisadores iniciantes em educação, saúde e ciências sociais. Porto Alegre: Artmed, 2009.

26. Sztompka P. A sociologia da mudança social. Rio de Janeiro: Civilização Brasileira, 1998, p. 463-502.

27. Tobar F, Yalour MR. Como fazer teses em saúde pública: conselhos e ideias para formular projetos e redigir teses e informes de pesquisa. Rio de Janeiro: Fiocruz; 2001. 172 p.

28. Vasconcelos KEL, Schmaller VPV. Promoção da Saúde: polissemias conceituais e ideopolíticas. In: Costa MDH, Vasconcelos KEL. Por uma crítica da promoção da saúde: contradições e potencialidades no contexto do SUS. São Paulo: Hucitec; 2014. p. 47-110.

29. Durkheim E. As regras do método sociológico. In: Durkheim E. As regras do método sociológico. 13. ed. São Paulo: Nacional; 1987.

30. Breilh J. Da Epidemiologia Linear à Epidemiologia Dialética. In: Breilh J. Epidemiologia crítica: ciência emancipadora e interculturalidade. Rio de Janeiro: Fiocruz; 2006. p. 191-218.

31. Pinheiro R, Luz MT. Práticas eficazes X modelos ideais: ação e pensamento na construção da integralidade. In: Pinheiro R. Construção da integralidade: cotidiano, saberes e práticas em saúde. Rio de Janeiro: UERJ/IMS/Abrasco; 2004, p. 7-34.

32. Giddens A. Sociologia. 4. ed. Porto Alegre: Artmed; 2006.

33. Goffman E. Manicômios, prisões e conventos. 2. ed. São Paulo: Perspectiva; 1987.

34. Schütz A. Fenomenologia e relações sociais. Rio de Janeiro: Zahar; 1979.

35. Glasse B, Strass A. The Discovery of the grounded theory: strategies for qualitative research. New York:

Transaction; 1967.

36. Von Mises L. The last Knight of liberalism. Alabama: Auburn; 2007.

37. Han BC. A sociedade do cansaço. Petrópolis: Vozes; 2015.

38. Dubet F. Sociologie de l'expérience. Paris: Seuil; 1994.

39. Touraine A. Pensar de outro modo. Lisboa: Instituto Piaget; 2007. Coleção Epistemologia e Sociedade

40. Beck U. Ciência para além da verdade e do esclarecimento? Reflexividade e crítica do desenvolvimento científico. In: Beck U. Sociedade de Risco. Rumo a uma outra modernidade. São Paulo: Editora 34; 2010. p. $235-247$.

41. Žižek S. A visão em paralaxe. São Paulo: Boitempo; 2008.

42. Mészáros I. A montanha que devemos conquistar. São Paulo: Boitempo; 2014.

43. Sahlins M. Cultura e razão prática. Rio de Janeiro: Zahar; 1979.

44. Wacquant L. As duas faces do gueto. São Paulo: Boitempo; 2008.

45. Hannerz U. Fluxos, Fronteira, Híbridos: Palavras-chave da antropologia transnacional. Revista Mana. 1997; 3(1):7-39.

46. Augé M. Não lugares: introdução a uma antropologia da sobremodernidade. Lisboa: 90 Graus; 2005.

47. Lévi-Strauss C. A Eficácia Simbólica. In: Lévi-Strauss C. Antropologia Estrutural. São Paulo: Cosac Naify; 2008.

48. Mauss M. Ensaio sobre a Dádiva. In: Mauss M. Sociologia e Antropologia. São Paulo: Cosac \& Naify; 2003. 
49. Meyer J. Pesquisa-ação. In: Pope C, Mays M. Pesquisa qualitativa em saúde. 3. ed. Porto Alegre: Artmed; 2009. p. 135-146.

50. Kenn J. O estudo de caso. In: Pope C, Mays M. Pesquisa qualitativa em saúde. 3. ed. Porto Alegre: Artmed; 2009. p. 127-134.

51. Yin R. Estudo de Caso. Porto Alegre: Artmed; 2009.

52. Lefèvre AMC, Lefèvre F, Cardoso MRL, et al. Assistência Pública a Saúde no Brasil: estudo de seis ancoragens. Saúde e Soc. 2002; 11(2):35-47.

53. Rabinow P. Artificialidade e iluminismo: da sociobiologia à biossociabilidade. In: Rabinow P. Antropologia da razão. Rio de Janeiro: Relume Dumará; 1999. p. 135-157.
54. Boyce RWD. Falácias de interpretação de dados históricos e sociais. In: Bauer MW. Pesquisa qualitativa com texto, imagem e som - um manual prático. 8. ed. Petrópolis: Vozes: 2010. p. 445-469.

55. Abrasco. Plano diretor da Comissão de Ciências Sociais e Humanas em Saúde. Triênio 2017-2019. [internet]. [acesso em 2018 jul 10]. Disponível em: https:// www.abrasco.org.br/site/comissaodecienciassociaisehumanasemsaude/wp-content/uploads/sites/5/2018/03/planodiretorCCSHS_trienio20172019. pdf.

Recebido em 13/07/2018

Aprovado em 04/12/2018

Conflito de interesses: inexistente

Suporte financeiro: não houve 